ESTUDos RBEP

\title{
Ensino colaborativo para o apoio à inclusão escolar: práticas colaborativas entre os professores
}

Carla Ariela Rios Vilaronga

Enicéia Gonçalves Mendes

\begin{abstract}
Resumo
Para uma educação que atenda às demandas de todos os alunos, é necessário pensar em estratégias que busquem o sucesso na aprendizagem, entre elas o modelo de ensino colaborativo, quando o professor da sala comum trabalha em colaboração com o docente de educação especial. Nesse sentido, o objetivo deste trabalho consiste em analisar as experiências práticas de ensino colaborativo dos professores de educação especial do município de São Carlos-SP, que participaram de uma formação na temática em 2011. O estudo é baseado na pesquisaação colaborativa. Os dados analisados trazem exemplos de coensino em diferentes estágios e reflexões sobre os fatores que podem contribuir para essa realidade na escola.
\end{abstract}

Palavras-chave: formação de professores; inclusão escolar; ensino colaborativo. 


\section{Abstract \\ Co-teaching for supporting school inclusion: collaborative practices among teachers}

In order to have an education that meets the demands of all students, it is necessary to think about strategies that seek successful learning, among them, there is the collaborative teaching model. In this model, the general teacher works in collaboration with the special education teacher. Accordingly, the objective of this study was to analyze practical experiences in collaborative teaching of special education teachers, who participated in a training on the topic in 2001, in São Carlos-SP. The study is based on the collaborative action research. The data analyzed bring examples of co-teaching in different stages and reflections about the factors that may contribute to this reality in school.

Keywords: teacher education; school inclusion; co-teaching.

\section{Introdução}

O debate acerca da inclusão escolar é assunto recorrente em nosso País, principalmente pelo aumento de alunos com deficiência matriculados nas escolas regulares, porém faltam indicadores para monitorar o processo. Os que acenam com estatísticas promissoras muitas vezes não possuem dados confiáveis ou não complementam seus estudos com descrições de quem é esse alunado e de como está sua situação educacional. Especificamente, se eles estão tendo acesso ao currículo, se estão se socializando na direção desejável e se são socialmente aceitos na escola. (Capellini, 2001; Santos, 2002; Rosa, 2003)

Estudos do grupo de pesquisa da Universidade Federal de São Carlos (Ufscar) -"Formação de Recursos Humanos e Ensino em Educação Especial (Foreesp)" - mostram que faltam aspectos básicos para garantir não apenas o acesso, mas a permanência e o aprendizado desses alunos com necessidades educacionais especiais, matriculados em classes comuns. Entretanto, é preciso considerar que se trata de um desafio considerável construir uma escola inclusiva num país com tamanha desigualdade (Mendes, 2007).

Thousand e Villa (1989) propuseram duas características para uma escola se tornar inclusiva: gastar tempo e energia formando a equipe escolar e capacitar equipes educacionais para tomar decisões de forma colaborativa. Porém, estudos sobre inclusão escolar têm demonstrado que os profissionais da escola que atuam individualmente nas salas de aula não possuem respostas para a maior parte das dificuldades apresentadas pelos estudantes e não são capazes de realizar processos reais de ensino para alunos com deficiência quando trabalham individualmente. 


\section{A formação de professores no contexto inclusivo}

A proposta de educação inclusiva se tornou um dos focos da política educacional vigente, incitada pelos movimentos sociais e tendo como proposta a equiparação de oportunidades para as pessoas até então excluídas socialmente. (Mendes, 2002).

Na Lei de Diretrizes e Bases da Educação Nacional no 9.394/96 (Brasil, 1996), assim como no Plano Nacional de Educação (PNE)/ 01, é previsto que o Atendimento Educacional Especializado (AEE) deve ocorrer preferencialmente na rede regular de ensino. As Diretrizes Nacionais para a Educação Especial na Educação Básica (Resolução CNE/CEB nº 2/2001 - Brasil, 2001), com destaque os artigos $3^{\circ}, 8^{\circ}$ e 12 , enfatizam que os alunos com necessidades educacionais especiais deveriam ser educados preferencialmente nas classes comuns das escolas regulares.

Diante desse contexto, precisaria estar prevista nas políticas municipais, estaduais e federais de educação a capacitação de professores especializados em educação especial, que atuariam em consonância com os professores das salas regulares. Com uma formação debilitada no que tange à educação especial, com cursos que na maioria das vezes não correspondem à realidade das escolas e sem troca efetiva com os professores especialistas em educação especial (quando fazem parte do corpo de profissionais da escola), os professores recebem todos os anos alunos com as mais distintas deficiências. O discurso de obrigatoriedade da matrícula e o enfraquecimento da prática pedagógica desse professor que não encontra espaços efetivos de troca e de formação faz com que a política real da inclusão se torne cada vez mais distante e mais utópica nas escolas públicas do País.

Em contraponto, na política atual, os professores de educação especial possuem uma demanda excessiva de atendimento individual nas salas de recursos multifuncionais, não existindo tempo para a formação especifica do profissional durante a carga horária de trabalho e para a atuação em colaboração com o professor da sala comum.

\section{A proposta de ensino colaborativo (coensino)}

Visando à proposta de ensino colaborativo, Conderman; Bresnahan; Pedersen (2009), enfatizam que é preciso discutir na escola questões relacionadas ao tempo de planejamento em comum entre o professor de educação especial e o professor da sala regular; aos conteúdos que devem ser incluídos no currículo; às adaptações curriculares; à distribuição de tarefas e responsabilidades; às formas de avaliação; às experiências em sala de aula; aos procedimentos para organização da sala; à comunicação com alunos, pais e administradores; ao acompanhamento do progresso de aprendizagem dos alunos; às metas para o Plano Educacional Individualizado dos alunos com deficiência. 
A proposta implica a redefinição do papel dos professores de ensino especial, como apoio centrado na classe comum e não somente serviços que envolvam a retirada dos alunos com deficiência das salas de aula regulares (Wood, 1998). O conjunto da literatura relacionada à temática revela que, quando eficazmente implementado, pode haver benefício para todos os estudantes, para o crescimento profissional, para o suporte pessoal e para a melhoria na motivação para ensinar (Walther-Thomas; Bryant; Land, 1996; Walther-Thomas, 1997; Walther-Thomas; Korineck; MC Laughin, 1999; Argueles; Hughes; Schumm, 2000, etc.). No entanto, quando não há um planejamento cuidadoso ou os papéis são indefinidos, esse tipo de suporte pode resultar em dificuldades para ambos os professores e também para os gestores (Argueles; Hughes; Schumm, 2000; Gately; Gately, 2001).

Mendes (2006) diz ser "necessário que se faça uma pesquisa mais engajada nos problemas da realidade e que tenham implicações práticas e políticas mais claras" (p. 402). Para que o contexto inclusivo não permaneça somente na retórica, deve-se pensar em formação de recursos humanos, em condições de trabalho para esse professor e em espaço de diálogo entre os formadores (no caso, a universidade) e a escola.

O trabalho baseado no ensino colaborativo, também conhecido como coensino, entre professores de educação especial e da sala regular, faz parte da proposta de alguns países para a inclusão escolar de alunos com deficiência, sendo esta apontada como uma das mais relevantes. No Brasil, esse modelo não é conhecido e/ou realizado pela maioria dos municípios, sendo utilizado apenas em casos pontuais e experimentais. Nessa direção, o objetivo principal deste trabalho consiste em analisar as experiências práticas em ensino colaborativo, dos professores de educação especial do município de São Carlos-SP, que participaram de uma formação na temática no segundo semestre de 2011.

\section{Metodologia e procedimentos de investigação}

O presente estudo é baseado na modalidade da pesquisa-ação colaborativa. Nesse tipo de estudo, o pesquisador leva ideias de práticas ao campo de pesquisa para causar algum impacto sobre o ambiente, e os participantes, sobre os quais coletou os dados (Brantingler et al., 2005); busca explanar e diagnosticar uma situação ou um problema prático que se quer melhorar ou resolver (Pereira, 1998); planeja uma ação; tem uma ação, observa esse processo de mudança e reflete sobre esses processos, possibilitando um novo replanejamento (Kemmis; Wilkinson, 2008). Esta abordagem foi escolhida para o estudo, pois, ao mesmo tempo que atende à necessidade de intervenção, produz conhecimento científico na área de educação especial.

Participaram desta pesquisa como pesquisadores colaboradores quatro professores com formação em educação especial que atuam na rede regular de ensino de São Carlos-SP. Para trabalhar em coensino com o 
professor de educação especial, foram convidados quatro professores que atuam nos anos iniciais de ensino da sala regular. Todos os sujeitos (ou responsáveis, no caso dos alunos) assinaram o Termo de Consentimento Livre e Esclarecido antes de iniciar o trabalho. Os nomes aqui apresentados são fictícios, selecionados pelos sujeitos da pesquisa.

O instrumento Roteiro para escrita do Diário de campo é um dos instrumentos utilizados para a coleta do projeto de doutorado e foi selecionado para este texto com o objetivo de nortear a escrita do professor de educação especial, sobre o contexto da escola regular e das atividades de coensino (Mendes, 2007).

\section{Resultados}

O curso, elaborado durante a pesquisa de doutorado entre os meses de agosto e dezembro de 2011, com duração de 60 horas entre parte teórica e prática, teve como objetivo possibilitar a ampliação dos conhecimentos sobre a temática do coensino para professores de educação especial que atuam na rede regular de ensino; discutir as experiências individuais e coletivas de implantação do coensino na rede regular de São Carlos-SP; refletir em grupo sobre processos de ensino e aprendizagem de alunos com necessidades educacionais especiais matriculados na rede regular de ensino.

O município de São Carlos-SP iniciou um projeto-piloto de trabalho no formato de coensino em 2011. O curso proporcionou momentos de reflexão ao professor de educação especial/ensino colaborativo, de como estava sendo o trabalho realizado em sala junto ao professor da sala comum, sem formação específica em educação especial. Os relatos apontam diferentes estágios da proposta de coensino e diferentes relações no que tange à colaboração, como se observa nas análises que seguem.

\section{O caso Cecília}

A professora de educação especial Cecília tem 28 anos, é formada em Pedagogia pela Universidade Estadual Paulista (Unesp) - Araraquara (2005), tendo uma formação específica na área de educação especial. Possui especialização em "Educação Infantil e a Escola de Nove Anos" (2009) e, entre os diversos cursos de formação continuada realizados nos últimos cinco anos, destaca: "Curso de Extensão Aciepe - Brinquedoteca para Todos" (60 horas); "Curso de Extensão Aciepe - Educação Especial" (60 horas); "Curso Básico de Libras" (30 horas); "Curso de Atualização Letra e Vida" (180 horas); "Curso de Introdução à Libras" (30 horas).

Atuou como professora do ensino fundamental por cinco anos. Trabalhava especificamente na rede regular de ensino de São Carlos-SP como professora de ensino colaborativo, contratada em caráter temporário há cinco meses, quando iniciou o curso. Em seu cargo atual, prioriza 
"adaptação curricular nas diferentes disciplinas; Interação aluno - aluno/ aluno - professor; Alfabetização/Conceitos básicos de matemática e Atividades de estimulação oral, auditiva e visual". Iniciou o curso de formação proposto com a seguinte expectativa: "Como o trabalho do ensino colaborativo é novo e se está iniciando sua implementação, é de extrema importância o estudo de teorias que envolvam esse tema para adquirirmos conhecimentos para colocarmos em prática." (Cecília, questões iniciais, agosto de 2011).

O caso selecionado por ela para discussão durante o curso foi o do aluno Conrado, de 14 anos de idade, que frequentava a $6^{\mathrm{a}}$ série do ensino fundamental. O aluno, segundo a professora, apresentava "Dificuldades motoras, comprometimento cognitivo". O professor com quem ela atuou em coensino, Celio, lecionava a disciplina de ciências biológicas.

Relato escrito - 31/8/2011

Fizemos uma prova baseada em figuras, cujo objetivo era o aluno apontar quais os hábitos deveriam ser evitados para que não fosse contaminado por doenças causadas pela falta de higiene.

Acompanhei e auxiliei o aluno em sua avaliação enquanto o professor auxiliava os outros alunos.

$[\ldots]$

O professor da sala regular, além de auxiliar os outros alunos, também se mostrou atencioso em relação ao aluno Conrado.

Terminada a prova, o aluno se remeteu ao professor para mostrar sua avaliação. O professor realizou questões orais para verificar se o aluno havia compreendido a atividade e o conteúdo trabalhado. Sentimos que a atividade foi satisfatória, para contemplar a participação do aluno.

Relato escrito - 28/9/2011

A atividade desenvolvida [...] tratou do conteúdo sobre as "Partes da planta e suas funções". O objetivo da atividade era levar o aluno a compreender os nomes e as funções que cada parte da planta contém. Foram utilizados diferentes materiais para o desenvolvimento da atividade e a atividade final (de avaliação do conteúdo aprendido) adaptada em forma de colagem para que o aluno pudesse fazê-la sem dificuldade.

O aluno não era capaz de participar de todas as atividades sem adaptações [...] o aluno não consegue escrever de forma convencional, por isso, enquanto os alunos copiavam da lousa, eu ia mostrando as figuras e as explicações no computador para o aluno.

A explicação do conteúdo já havia sido feita na aula anterior e, como Conrado tinha faltado, o professor foi em sua carteira enquanto os outros alunos copiavam da lousa e explicou o conteúdo para ele, apoiando-se na apresentação. Nesse momento, invertemos os papéis, fiquei observando a sala e tirando suas dúvidas enquanto o professor dava uma atenção mais individualizada a Conrado.

O aluno se sentiu muito feliz, dada a atenção do professor, conversou sobre o conteúdo, fez perguntas.

Relato escrito - 19/10/2011

No dia 19/10, aula de Ciências, enquanto o professor passava o conteúdo na lousa, pesquisei algumas figuras e levei em forma de apresentação no Power Point para ir mostrando ao aluno Conrado, para ir se interando do

\footnotetext{
${ }^{1}$ Trechos dos diários de campo escritos pelos professores de educação especial, sujeitos na pesquisa. Optou-se pela fidedignidade a transcrição do material.
} 
assunto (pois o aluno não lê nem escreve), e fomos conversando sobre o mesmo assunto enquanto os outros alunos copiavam.

No momento da explicação do professor, este trouxe imagens para serem apresentadas no retroprojetor; desta forma todos puderam visualizar as imagens e compreender melhor o conteúdo.

\section{O caso Benício}

Benício tem 29 anos, é formado em Pedagogia pela Universidade Estadual Paulista (Unesp) - Araraquara (2009), com conteúdos que abordavam também a educação especial. Na sua formação continuada dos últimos cinco anos, relata cursos como: Soroban (40 horas) e Libras (60, 60 e 40 horas). Atuou cerca de dois anos na educação infantil e no ensino fundamental. No início do curso era contratado em caráter temporário como professor de ensino colaborativo da rede regular de São Carlos-SP, onde atuava há cinco meses.

Iniciou o curso com a expectativa de que a temática poderia contribuir para sua formação profissional e, consequentemente, para as atividades que realiza no espaço escolar especificamente: "Dando embasamento teórico para o meu trabalho. A troca de experiências no curso também é uma oportunidade para sanar dúvidas vividas naquele momento". (Benício, questões iniciais, agosto de 2011).

O caso selecionado pelo Benício foi da aluna Betânia, que cursava o $3^{\circ}$ ano do ensino fundamental. As dificuldades relatadas pelo professor se referem à "cognição, motricidade; assimilar conteúdos; relacionar fatos; coordenação motora e linguagem". O professor que trabalhou com Benício nessa experiência tem formação em magistério e licenciatura em história.

Relato escrito - 22/9/2011

A atividade é proposta para a aluna para exercitar a habilidade de coordenação visomotora dela, que, embora tenha vontade de copiar as atividades que estão na lousa, não consegue e se dispersa, vai ao banheiro, bebe água, ora fica arrumando o material, etc.

A aluna, após terminar a atividade da parlenda, mostrou a atividade para o professor Benício e mostra interesse em se envolver na rotina da classe [...]. Sua interação com os alunos é um pouco superficial por conta da comunicação, pois a aluna tem dificuldades em articular suas ideias e se expressar oralmente, embora tenha uma excelente memória e guarde o nome de todos os alunos.

Relato escrito - 10/11/2011

O professor está passando um simulado da Prova Brasil, conteúdo de português, com os alunos. A aluna sabe o meu horário e quando chego já está me aguardando com uma cadeira ao lado dela; como o conteúdo do simulado é muito extenso, continuo com as atividades de recorte e colagem de figuras para depois reconhecer as palavras, escrever e separar as sílabas.

A aluna faz atividades separadas, pois não acompanha o ritmo da classe, isto é, dos conteúdos, tendo que ser repertoriado o tempo todo em relação aos conteúdos. 


\section{O caso Eduarda}

Eduarda tem 30 anos, é formada em Pedagogia, com habilitação em Educação Especial, também pela Universidade Estadual Paulista (Unesp) - Araraquara (2006), e possui especialização em "Psicopedagogia Educacional e Clínica" (2009). Especificamente, no que tange à formação continuada, relata que realizou os seguintes cursos nos últimos cinco anos: "III e IV Curso de Formação de Gestores e Professores de Educação Especial" (40 horas); "V Ciclo de Conferências - A aprendizagem através da interdisciplinaridade" (10 horas); "Iniciação ao Autismo" (120 horas).

Tem experiência de quatro anos como professora do ensino fundamental e era contratada, em caráter temporário, como professora de sala de recursos há cinco meses. Sua expectativa quando iniciou o curso foi de que este a ajudasse "no atendimento específico aos alunos do ensino colaborativo e também pensar atividades e como trabalhar dentro da sala regular com esses alunos" (Eduarda, questões iniciais, agosto de 2011).

O caso selecionado pela Eduarda foi o da aluna Emily, que tem 9 anos de idade e cursa o $3^{\circ}$ ano do ensino fundamental. A professora relata que a aluna apresenta "déficit na aprendizagem devido a atitudes imaturas [...] em relação à idade, com falas incoerentes". A professora que atuou com Eduarda tem formação em Pedagogia e habilitação em Educação Especial.

Relato escrito 10-14/9/2011

Durante o acompanhamento da aluna na sala de aula regular, as atividades desenvolvidas eram de português, interpretação e leitura. A aluna não consegue realizar leitura, sendo assim, a professora a questionava sobre os fatos ocorridos na história. Nesta sala há muitos problemas de indisciplina, alguns alunos que também apresentam dificuldades de aprendizagem, mas a professora consegue adaptar para os alunos as atividades e também para a Emily.

\section{Relato escrito - 21/9/2011}

No dia 21/9 as atividades eram: término de reescrita de português e atividades de matemática. Para a classe, a professora estava explicando uma lista de exercícios com problemas envolvendo as 4 operações. Para Emily e outros alunos que apresentam dificuldades na matemática, ela elaborou uma lista de exercícios com situações-problema também, mas com bastantes figuras e objetos.

Foi difícil no início essa atividade, por causa da grande resistência de Emily, mas aos poucos, com conversa, ela começou a realizar as atividades. Primeiro, eu ficava ensinando-a, quase resolvendo, depois ela passou a se orientar pelas atividades e resolvia da sua maneira e depois vinha até mim perguntar se estava correto, quando então eu fazia as intervenções necessárias.

As atividades realizadas nessa semana eram de matemática, durante o período que estive na sala de aula no coensino.

[...]

A professora mudou a estratégia de ensino para trabalhar com a aluna, e a professora do coensino ajudou durante a resolução das atividades. 
Marisol tem 52 anos, é formada em Pedagogia pela Universidade São Judas Tadeu - São Paulo (1985) e possui duas especializações: Educação Especial (2007) e Psicopedagogia (2010). Dos cursos de formação continuada que realizou entre 2007 e 2001, destaca: "Música em Movimento" (90 horas); "Iniciação em Libras" (190 horas); "Estimulação Sensorial" (90 horas); "Iniciação ao Autismo" (120); "Escola que protege" (90 horas).

Trabalhou oito anos como professora de educação infantil, quatro anos no ensino fundamental e 30 meses na Associação de Pais e Amigos dos Excepcionais (Apae). No início do curso, trabalhava como professora da sala de recursos da Rede Municipal de São Carlos-SP. Sua expectativa inicial do curso é que este conseguiria trazer "ideias novas, metodologias, propostas e relato de trocas de experiências, acredito que isso iria facilitar nosso trabalho" (Marisol, questões iniciais, agosto de 2011).

O caso selecionado por Marisol foi o do aluno Milton, de sete meses de idade, que frequentava a fase I da educação infantil. Marisol relatou seu trabalho com as três professoras da sala de aula regular de Milton durante o curso.

Relato Escrito - 11/10/2011

Fizemos exercícios para o fortalecimento dos músculos das costas, para que ele possa se sentar. Tem demonstrado melhoras e avanços nos atendimentos. Já reconhece minha voz e sorri quando me vê.

Relato Escrito - 14/10/2011

Brincamos no tatame e em frente ao espelho. Permanece mais tempo sentado, porém com ajuda. Segura o próprio pé quando está sentado. De bruços, consegue se virar e desvirar sozinho. Para ficar sentado, precisa de ajuda, mas já se mantém.

\section{Análises das experiências}

Os relatos dos professores de educação especial que participaram do curso de ensino colaborativo, e que olharam as suas práticas como professores colaboradores, demonstram que a conquista pelo trabalho nesse modelo é um processo, caminho que começa pela definição de papéis que cada profissional (de ensino comum e especial) desempenha em sala de aula.

No que tange a esses papéis, French (2002) diz que na colaboração o professor especialista e o professor da sala comum devem ter um projeto mínimo de atividade com os alunos com deficiência, em concordância com o que está sendo trabalhado no currículo da sala. O professor da sala comum deve obter informações com o professor consultor sobre os estudantes, para quem os planos individualizados foram construídos, e discutir com ele sobre as adaptações individuais para esses alunos. Nos 
casos analisados, percebemos que esses papéis podem ser diferenciados e confusos em alguns momentos, principalmente pelo trabalho com esse modelo na rede regular de ensino.

Entre os fatores cruciais para o sucesso do trabalho com o modelo de coensino, Lerh (1999) cita três aspectos que são apontados também pelos sujeitos pesquisados nessa experiência de coensino:

1. Participação voluntária dos profissionais, tendo o ensino colaborativo como oportunidade de crescimento profissional, encorajando esse tipo de trabalho no contexto escolar - fato que se conseguiu alcançar com a experiência vivenciada no segundo semestre de 2011, quando os profissionais de educação especial foram convidados para fazer o curso e fizeram a proposta para os professores da sala comum.

2. Oferecer aos professores tempo suficiente para o planejamento do coensino pela estrutura escolar. Em alguns casos, encontrou-se tempo de planejamento comum nos intervalos das aulas ou em momentos nos quais os alunos realizavam atividades práticas. Em outros casos, esse planejamento não ocorreu, sendo realizado inicialmente o apoio em sala de aula, o que ilustra que existem estratégias de planejamento na atual estrutura escolar, porém, os professores dizem que são necessárias mudanças na escola, para que exista um planejamento sistematizado na busca de atividades inclusivas baseadas no currículo dos alunos.

3. Oferecer formação específica para os profissionais, visando ao trabalho colaborativo. Percebemos o quanto uma formação baseada nos pressupostos de colaboração influencia no trabalho realizado por esses profissionais na escola. Percebe-se que discutir sobre os casos e sobre a experiência da sala de aula proporcionou avanço a eles no que tange a sua prática e olhar sobre ela.

É interessante ressaltar também que os relatos apontam para diferentes níveis de colaboração (Gately; Gately, 2001), com graus variados de interação e colaboração entre os profissionais da educação regular e da especial:

- Estágio inicial: eles se comunicam superficialmente, criando limites e tentativas de estabelecer um relacionamento profissional entre si, a comunicação é formal e infrequente;

- Estágio de comprometimento: a comunicação entre eles é mais frequente, aberta e interativa, o que possibilita que eles construam o nível de confiança necessário para a colaboração;

- Estágio Colaborativo: eles se comunicam e interagem abertamente, sendo que a comunicação, o humor e um alto grau de conforto é experienciado por todos. Eles trabalham juntos e um complementa o outro. 
Nos casos relatados, percebe-se o percurso para se chegar a colaboração, mas ainda não se pode afirmar a chegada ao "estágio colaborativo". Caminho que não depende somente dos profissionais da escola, mas de toda uma mudança histórico e cultural, principalmente no que se refere à imagem de que os profissionais da educação especial sejam os "experts" e que entrariam na sala de aula somente para realizar um trabalho individualizado. (Pugach; Johnson, 1989).

\section{Considerações finais}

Concluindo, podemos dizer que a literatura científica relacionada ao coensino, apesar de promissora, evidencia a necessidade de mais estudos sobre a colaboração entre o professor regular e o de educação especial nas escolas, bem como a preparação efetiva dos profissionais que atuam em Educação Especial. Como uma das conquistas das reflexões realizadas durante o curso, o trabalho em formato de ensino colaborativo, que era uma proposta ainda não fortalecida no município de São Carlos, foi aprovada por um grupo de professores para compor o Plano Municipal de Educação dos próximos 10 anos. Processo que mobiliza o debate e futuras formações.

Espera-se, com essa proposta, que se realize uma formação para educação inclusiva mais próxima a realidade da escola, dos professores e dos alunos com deficiência matriculados na rede regular de ensino. Assim como ferramentas e materiais didáticos específicos para formação de professores para o trabalho no modelo de ensino colaborativo.

\section{Referências bibliográficas}

ARGÜELLES, M. E.; HUGHES, M. T.; SCHUMM, J. S. Co-Teaching: a different approach to inclusion. Principal, Reston, v. 79, n. 4, p. 50-51, 2000.

BRANTLINGER, E. et al. Qualitative studies in special education. Exceptional Children, v. 71, n. 2, p. 195-207, 2005.

BRASIL. Lei n. 9.394, de 20 de dezembro de 1996. Estabelece as diretrizes e bases da educação nacional. Diário Oficial da União, Brasília, DF, 23 dez. 1996, v. 134, n. 248, seção I, p. 27833-27841.

BRASIL. Conselho Nacional de Educação. Câmara de Educação Básica. Resolução CNE/CEB 2/2001. Diretrizes nacionais para a educação especial na educação básica. Diário Oficial da União, Brasília, DF, 14 set. 2001, Seção 1E, p. 39-40. 
CAPELLINI, V. L. M. F. A inclusão de alunos com necessidades educacionais especiais em classes comuns: avaliação do rendimento acadêmico. 2001. Dissertação (Mestrado em Educação Especial) Programa de Pós-Graduação em Educação Especial, Universidade Federal de São Carlos, São Paulo, 2001.

CONDERMAN, G.; BRESNAHAN, V.; PEDERSEN, T. Purposeful coteaching: real cases and effectives strategies. California: Corwin Press: Thousand Oaks, 2009.

FRENCH, N. K. The shifting roles of school professionals. California: Corwin Press, 2002.

GATELY, S. E.; GATELY, F. J. Understanding coteaching components. Teaching Exceptional Children, v. 33, n. 4, p. 40-47, mar./apr. 2001.

KEMMIS, Stephen; WILKINSON, Mervyn. A pesquisa-ação participativa e o estudo da prática. In: DINIZ-PEREIRA, Júlio Emilio (Org). A pesquisa na formação e o trabalho docente. Belo Horizonte: Autêntica, 2008. p. 43-66.

LEHR. A. E. The administrative role in collaborative teaching. NASSP Bulletin, Las Vegas, v. 83: n. 611, p. 105-111, dec. 1999.

MENDES, E. G. Inclusão marco zero: começando pelas creches. Araraquara: Junqueira\&Marin, 2010.

MENDES, E. G. Projeto S.O.S. inclusão: avaliação de um programa de consultoria colaborativa de apoio à inclusão escolar. Relatório Técnico de Produtividade em Pesquisa - CNPq. São Carlos: UFSCar, 2007. $112 \mathrm{p}$.

MENDES, E. G. A radicalização do debate sobre inclusão escolar no Brasil. Revista Brasileira de Educação, Campinas, v. 11, n. 33, p. 387-405, set./dez. 2006.

MENDES, E. G. Perspectivas para a construção da escola inclusiva. In: PALHARES, M. S.; MARINS, S. Escola inclusiva. São Carlos: Edufscar, 2002. p. 61-86.

PEREIRA, E. M. A. Professor como pesquisador: o enfoque da pesquisaação na prática docente. In: GERALDI, C. M. G.; FIORENTINI, D.; PEREIRA, E. M. A. (Org). Cartografias do trabalho docente. Campinas: Mercado das Letras, 1998. p. 153-181.

PUGACH, M. C.; JOHNSON, L. J. The challenge of implementing collaboration between general and special education. Exceptional Children, v. 56, n. 3, p. 232-235, 1989. 
ROSA, L. C. S. Formação continuada de atendentes para inclusão de crianças com necessidades educacionais especiais em creches. 2003. Dissertação( Mestrado em Educação Especial) - Programa de PósGraduação em Educação Especial, Universidade Federal de São Carlos, São Paulo, 2003.

SANTOS, N.A.S. A perspectiva da inclusão escolar na educação infantil de Juiz de Fora. 2002. Dissertação (Mestrado em Educação Especial) - Programa de Pós-Graduação em Educação Especial, Universidade Federal de São Carlos, São Paulo, 2002.

THOUSAND, J. S.; VILLA, R. A. Enhancing success in heterogeneous schools. In: STAINBACK, S.; STAINBACK, W.; FOREST, M. Educating all students in the mainstream of regular education. Baltimore: Paul $\mathrm{H}$ Brookes, 1989. p. 89-104.

WALTHER-THOMAS, C. Co-teaching experiences: The benefits and problems that teachers and principals report over time. Journal of Learning Disabilities, 30, p. 395-407, 1997.

WALTHER-THOMAS, C.; BRYANT, M.; LAND, S. Planning for effective co-teaching: The key to successful inclusion. Remedial and Special Education, v. 17, n. 4, p. 255-264, 1996.

WALTHER-THOMAS, C.; KORINEK, L.; MCLAUGHLIN, V. L. Collaboration to support student's success. Focus on Exceptional Children, v. 32, n. 3, p. 1-18, 1999.

WOOD, M. Whose Job is it anyway? Educational roles in inclusion. Exceptional Children, v. 64, n. 2, p. 181-195, 1998.

Carla Ariela Rios Vilaronga, doutoranda em Educação Especial na Universidade Federal de São Carlos (UFSCar), é pedagoga no curso de licenciatura em Educação Especial da UFSCar, São Carlos, São Paulo, Brasil. crios@ufscar.br

Enicéia Gonçalves Mendes, doutora em Psicologia pela Universidade de São (USP), é professora do Departamento de Psicologia e coordenadora do Programa de Pós-Graduação em Educação Especial da Universidade Federal de São Carlos (UFSCar), São Carlos, São Paulo, Brasil.

egmendes@ufscar.br

Recebido em 31 de agosto de 2013.

Aprovado em 17 de dezembro de 2013. 